\title{
The Relationship Between Quality of Life, Functional Capacity, Physical Activity and Performance Levels in Chronic Venous Disease
}

\author{
Sema Ozberk ${ }^{1}$, Didem Karadibak ${ }^{2}$, Dundar Ozalp Karabay, ${ }^{3}$ Muslum Polat ${ }^{4}$
}

\footnotetext{
1) Dokuz Eylul University Institute of Health Science, Izmir / Turkey

2) Dokuz Eylul University School of Physical Therapy and Rehabilitation, Izmir / Turkey

3) Dokuz Eylul University School of Medicine Department of Cardiovascular Surgery, Izmir / Turkey

4) Dr Ersin Arslan Education and Research Hospital Department of Cardiovascular Surgery, Gaziantep / Turkey
}

\begin{abstract}
Objective: In this study we aimed to evaluate the relationship among the quality of life, functional capacity, physical activity and performance levels of individuals with chronic venous disease (CVD).

Methods: 210 individuals with CVD grade I-V according to the CEAP classification were included in the study. Functional capacity of individuals was evaluated by the 6-minute walk test (6MWT) and heart rate, blood pressure and oxygen saturations were assessed before and after the 6MWT. Physical activity level International Physical Activity Questionnaire (IPAQ), performance level sit-to-stand test and Quality of life VEnous INsufficiency Epidemiologic and Economic Study on Quality of Life Questionnaire (VEINES-QoL). The data for the study was calculated using the SPSS 20.0 package program.

Results: The study consisted of $143(\% 68,1)$ female, $67(\% 31,9)$ male individuals. The average of age was $39,2 \pm 10,1$ and body mass index (BMI) was 27,9 $\pm 6,32$. Quality of life has significant positive and low correlation with performance level $(r=0.161 \mathrm{p}<0.05)$, physical activity $(r=0.178 \mathrm{p}<0.05)$ and functional capacity $(\mathrm{r}=0.171 \mathrm{p}<0.05)$. In addition, there was a significant positive and moderate correlation in functional capacity with performance $(r=0.521 \mathrm{p}<0.001)$.

Conclusions: CVD has been reported as an important health problem that negatively affects the life quality of individuals (1). In individuals with chronic venous disease, the quality of life decreases when physical activity, functional capacity and performance are low. Considering the negative impact on public health due to high prevalence, we think that the data obtained in more cases can explain the evaluations in this study better.
\end{abstract}

Keywords: Chronic venous disease, Quality of Life, functional capacity.

Özberk S., Karadibak D., Karabay Ö., Polat M. The Relationship Between Quality of Life, Functional Capacity, Physical Activity and Performance Levels in Chronic Venous Disease. EJCM 2018; 06 (3): 97-101. Doi: 10.32596/ejcm.18.00397. 


\section{Introduction}

Chronic Venous Disease (CVD) is a vital health issue with high prevalence and apparent in loss working capacity with high-cost diagnosis and treatment and negative effects on life quality of an individual. ${ }^{(1)}$ There are many factors in its etiology and its foremost ones can be regarded as genetic predisposition, age, gender, obesity, pregnancy, staying up for a long time, intraabdominal malignancies, thrombophlebitis and previous leg injuries. ${ }^{(2,3)}$ Its incidence is reported in women as $2.6 \%$ and in men as $1.9 \%$ annually. It is seen in adult females as $25-33 \%$, in males $10-20 \%{ }^{(4)}$

Most widely used methods in the diagnosis of CVD are doppler ultrasonography (DUS) and CEAP (clinical, etiological, anatomical, pathophysiological) classification. In its treatment, pharmacological approach, compression and elevation treatment, pumping exercises, skin care and surgical techniques are applied. However, CVD's treatment methods have been still discussed, it is not curable completely. ${ }^{(4,5)}$

Certain complaints such as venous hypertension that occurs as a result of valve insufficiency and allows blood circulation to retard and varicosis which are formed by impairing tissue nutrition, pain, cramps, edema, itching, pigmentation, venous ulcers are observed. Overall decrease life quality. However, there is no wide study that researched quality of life, functional capacity, physical activity and performance levels in CVD patients. Therefore, the aim of this study to evaluate the relationship between quality of life, functional capacity, physical activity and performance levels of individuals with chronic venous disease.

\section{Materials and Methods}

Individuals were 210 CVD survivors, who referred to Research and Education Hospital, Cardiovascular Surgery clinic in Izmir and Gaziantep, Turkey.

Inclusion criteria were (i) aged 18 to 65 years; (ii) confirmed CVD stages I-V. Exclusion criteria were having (i) active ulceration (clinic stage VI), (ii) neurological and musculoskeletal disease history, (iii) metastatic condition presence, (iv) severe cardiac insufficiency and/or rhythm disorder diagnosis, (v) advanced psychological impairment, (vi) vestibular system problem, (vii) severe visual loss, (viii) chronic alcohol use history, (ix) pregnancy situation or (x) long-term cortisol treatment. Required permissions were obtained from local ethical committee and the patients were informed about the evaluations to be carried out and the purpose of the study and informed consent was acquired before inclusion.

This study was a cross-sectional prospective study. All tests were performed by the same physiotherapist and all evaluations lasted about 30 minutes. The patients were given resting periods between the tests.

Sociodemographic-clinical characteristics and CVD related data were assessed face to face interview and obtained from the records of cardiac surgery archive. The clinical level of participants was described with CEAP. With regard to diagnosis, treatment and screening; CEAP (clinical, etiological, anatomical, pathophysiological) classification is divided into 7 stages including according to the severity of clinical evidence $\mathrm{C} ; \mathrm{CO}=$ Normal, $\mathrm{C} 1=$ Spider/reticular veins, $\mathrm{C} 2=$ Varicose veins, $\mathrm{C} 3=$ Edema, $\mathrm{C} 4=$ Skin changes, $\mathrm{C} 5=$ recovered ulcer and $\mathrm{C} 6=$ Active ulcer. Etiologically, while called as $\mathrm{E}_{\mathrm{c}}=$ Congenital, $\mathrm{E}_{\mathrm{p}}=$ Primary, $\mathrm{E}_{\mathrm{s}}=$ Secondary; anatomically; described as $\mathrm{A}_{\mathrm{s}}=$ Superficial veins, $A_{p}=$ Perforan veins, $A_{d}=$ Deep veins; according to pathophysiology; $\mathrm{P}_{\mathrm{r}}=$ Reflux, $\mathrm{P}_{0}=$ Obstruction, $\mathrm{P}_{\mathrm{r}-\mathrm{o}}=$ Reflux and obstruction, $\mathrm{P}_{\mathrm{n}}=$ Pathology unknown. ${ }^{(1-3,5)}$

\section{Functional Capacity}

The functional capacity of the participants was measured by 6 Minute Walk Test (6MWT) which is a submaximal test. The 6MWT was indicated as a valid, reliable and useful test in patients with at least moderate to severe impairment by American Thoracic Society (ATS). The test was performed under the supervision of a physiotherapist in a flat surface on a 30 meter (every 3 meter is marked) straight corridor. A total of walking distance was written down at the end of 6MWT. Heart rate, blood pressure, dyspnea and fatigue levels were noted prior to the test, at the end of the test and 5 minutes recovery period. Dyspnea and fatigue were measured with Modified Borg Scale (MBS). MBS is conducted with a description corresponding to any number between 0-10. "0" means "none"; "10" means "very severe". ${ }^{(6,7)}$ 


\section{The Quality of Life}

The quality of life was assessed using VEnous INsufficiency Epidemiologic and Economic Study on Quality of Life Questionnaire (VEINES-QoL) (2013). VEINES-QOL is a standardized, 26- item, patient-reported questionnaire to assess the severity and frequency of venous insufficiency symptoms (questions 1,7; 10 items: heaviness, pain, leg swelling, night cramps, fatigue, burning sensation, throbbing sensation, itching, numbness in the legs, pain intensity), time of day when the symptoms are most pronounced (1 item, question 2), changes in the severity of symptoms during the past year (1 item, question 3 ), limitations in daily activities associated with venous insufficiency ( 9 item, questions 4,5,6), and the psychological impact on the functional status of patients with venous insufficiency measured during the previous 4 weeks ( 5 items, question 8). Lower scores refer to worse life quality. ${ }^{(2,8)}$

\section{Physical Activity Level}

The physical activity level assessed using International Physical Activity Questionnaire (IPAQ)-short form which questioned the physical activity in last 7 days. IPAQ-short form is a self-report questionnaire. Calculation of total scores of forms includes period (minutes) spent for walking, mild and severe activity and their frequency (days). From these calculations, a score is obtained as MET-minute. According to calculation result; conditions are determined as follows: $<500$ MET-min/week low physical active, 500-2500 MET-min/week moderate physical active, $>2500$ MET-min/week physical active. ${ }^{(9)}$

\section{Performance Level}

Lower limb performance level was evaluated with repeated sit to stand test. The patient sitting on a chair and stand up and the number of sit down and stand up was noted in 30 seconds. ${ }^{(10)}$

\section{Statistical Analysis}

All data were analyzed using SPSS 20.0 package program. Defining criteria were presented as average and percentage distribution. The validity of normal distribution of data was controlled with KolmogorovSmirnov test. Pearson and Spearman Correlation Analyses were used to evaluate the correlation. For signifi- cance level, it was regarded as $\mathrm{p}<0.05$.

\section{Results}

Initially, 254 patients diagnosed with CVD were recruited to the study. 226 (89\%) fulfilled the inclusion criteria. But, 16 individuals could not complete the tests and questionnaires given to them. Therefore, this allowed data to be obtained only on 210 participants.

The mean age and body mass index (BMI) of 210 (67 male, 143 female) individuals was $39,2 \pm 10,1$ years $($ mean $\pm S D)$ and $27,9 \pm 6,32 \mathrm{~kg} / \mathrm{m}^{2}$, respectively. $47 \%$ of individuals were stage II. Demographic and clinical characteristics of individuals are presented in Table 1.

Quality of life has significant positive and low correlation with performance $(r=0.161 \mathrm{p}<0.05)$, physical activity $(\mathrm{r}=0.178 \mathrm{p}<0.05)$, functional capacity $(r=0.171 \mathrm{p}<0.05)$. In addition, there was a significant positive and moderate correlation in functional capacity with performance $(r=0.521 \mathrm{p}<0.001)$ Table 2 .

\section{Discussion}

In this study, we assessed quality of life, functional capacity, physical activity and performance level of CVD patients. Performance level and functional capacity had significant correlation in CVD patients.

When gender distributions of participants with chronic venous disease are examined, women form the majority of the patients. Hence, in a study performed by Fiebig et al. (2010), it was determined that female population accounted for $70 \%$ of the cases with venous disease. ${ }^{(11)}$ In parallel to this, the number of females was identified to be higher $(67 \%)$ in the present study, as well.

In a study evaluating physical performance in individuals with and without venous ulcer, it is reported that venous ulcer reflects low performance level. In the study under discussion, it was observed that performance level was one of the primary determinants of functional capacity and so effects the life quality. Performance levels of patients were influenced in a negative way. In this regard, we think that a detailed evaluation is required for lower extremity performance level with specific tests and appropriate objective assessments. ${ }^{(12,13)}$ 
Table 1. Clinical characteristics of the patients according to genders

\begin{tabular}{|c|c|c|c|}
\hline & Female $n=143$ & Male $n=67$ & Total $n=210$ \\
\hline Gender (\%) & 68,1 & 31,9 & \\
\hline Age (year, $X \pm S D$ ) & $39.2 \pm 10.1$ & $38.1 \pm 12.17$ & $38.7 \pm 10.96$ \\
\hline $\mathrm{BMI}\left(\mathrm{kg} / \mathrm{m}^{2}, \mathrm{X} \pm \mathrm{SD}\right)$ & $29.24 \pm 5.66$ & $27.35 \pm 4.66$ & $28.61 \pm 5.41$ \\
\hline $\begin{array}{l}\text { CEAP } \\
\text { Stage I } \\
\text { Stage II } \\
\text { Stage III } \\
\text { Stage IV } \\
\text { Stage V }\end{array}$ & $\begin{array}{c}27(19) \\
80(56) \\
25(17.5) \\
9(6.2) \\
2(1.3)\end{array}$ & $\begin{array}{c}7(10.4) \\
19(28.4) \\
21(31.4) \\
17(25.3) \\
3(4.5)\end{array}$ & $\begin{array}{c}34(16.2) \\
99(47.1) \\
46(22) \\
26(12.4) \\
5(2.3)\end{array}$ \\
\hline $\begin{array}{l}\text { Quality of life } \\
\text { Min-max } \\
\text { 29-107 }\end{array}$ & $63.67 \pm 15.37$ & $69.47 \pm 16.67$ & $65.62 \pm 16.0$ \\
\hline $\begin{array}{l}\text { Functional capacity (m) } \\
\text { Min-max } \\
240-720\end{array}$ & $420.08 \pm 89.41$ & $468.08 \pm 99.04$ & $436.17 \pm 95.21$ \\
\hline $\begin{array}{l}\text { Physical activity } \\
\text { Low active } \\
\text { Moderately active } \\
\text { Vigorous active }\end{array}$ & $\begin{array}{c}16(7.2) \\
50(26.5) \\
77\end{array}$ & $\begin{array}{l}16(24.6) \\
19(33.3) \\
32(42.1)\end{array}$ & $\begin{array}{c}32(13) \\
69(28.8) \\
109(58.2)\end{array}$ \\
\hline $\begin{array}{l}\text { Performance } \\
\text { Min-max } \\
5-17\end{array}$ & $11.46 \pm 2.36$ & $12.76 \pm 2.07$ & $11.89 \pm 2.34$ \\
\hline
\end{tabular}

Table 2. Relationship between clinical evaluation parameters of patients

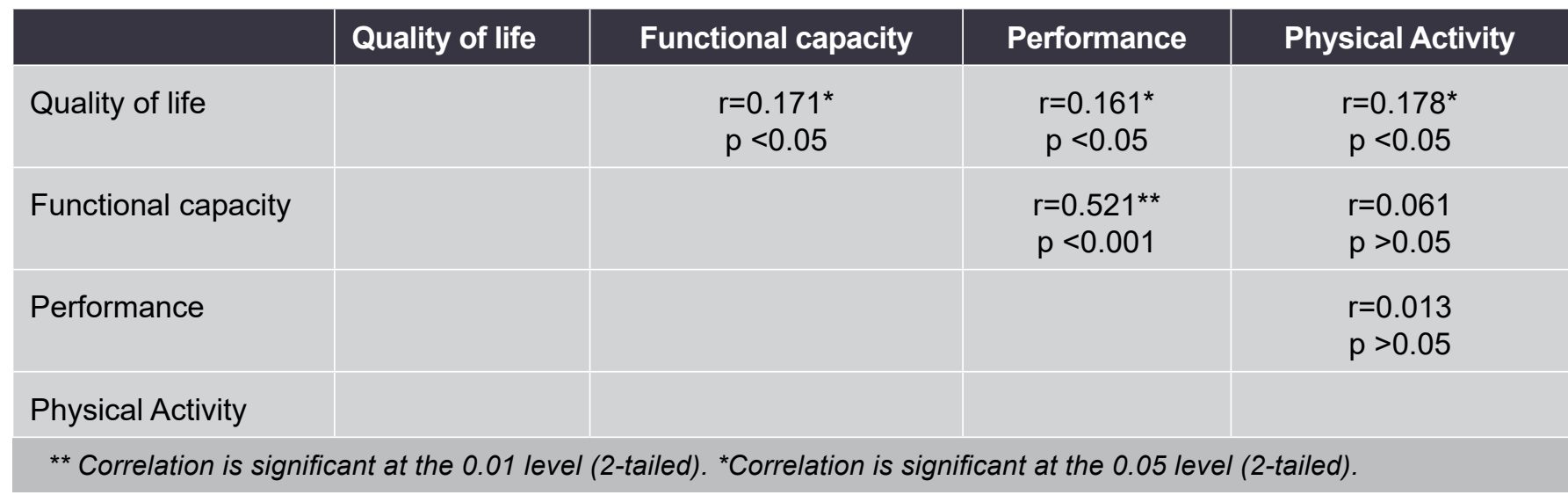

Although venous disease was emphasized to be a chronic disease affecting the quality of life negatively, it is stated that studies regarding this issue are still needed. In patients with chronic venous disease, it is reported in many studies that since it affects both physical and psychological health negatively, it reduces life quality. ${ }^{(14,15)}$ In a study conducted by Dias et al., the quality of life in participants with and without venous ulcer was compared and the group with venous ulcer was discovered to have a connection with lower physical health and insufficient functional capacity. ${ }^{(16)}$ It was noted in this study that when symptom severity and rate 
increased in patients, their quality of life decreased and they had lower social and psychological effects.

Conditions such as having more subjective evaluation batteries in the study and lower education level of patients diminish the competency of this paper in terms of that tests could be dealt with adequately and effectively. Nevertheless, as patients with chronic venous disease approached functional sufficiency with a broad perspective, it is an important study that it contributes to literature.

CVD has been reported as an important health problem that negatively affects the life quality of individuals. In individuals with chronic venous disease, the quality of life decreases when physical activity, functional capacity and performance are low. Considering the negative impact on public health due to high prevalence, we think that the data obtained in more cases can explain the evaluations in this study better.

\section{References}

1. Beebe Dimmer JL, Pfeifer JR, Engle JS, et al. The epidemiology of chronic venous insufficiency and varicose veins. Ann Epidemiol. 2005; 15:175-184.

2. Allan PL, Bradbury AW, Evans CJ et al. Patterns of reflux and severity of varicose veins in the general population Edinburgh Vein Study. Eur J Vasc Endovasc Surg. 2000; 20:470-477.

3. Chiesa R, Marone EM, Limoni $\mathrm{C}$ et al. Chronic venous insufficiency in Italy: the 24 cities cohort study. Eur J Vasc Endovasc Surg. 2005; 30:422-429.

4. Eklof B, Rutherford RB, Bergan JJ et al. Revision of the CEAP classification for chronic venous disorders: consensus statement. J Vasc Surg. 2004 Dec; 40(6):1248-52.

5. Moura RM, Goncalves GS, Nayesro TP, et al. Relationship between quality of life and the CEAP clinical classification in chronic venousdisease. Rev Bras Fisioter. 2010 Mar-Apr;14(2): 99-105. Epub 2010 May 14.

6. American Thoracic Society. ATS Statement: Guidelines for the six-minute walk test. Am J Respir Crit. Care Med. 2002; 166: 111-117.

7. Johnson MJ, Close L, Gillon SC, et al. Use of the modified Borg scale and numerical rating scale to measure chronic breathlessness: a pooled data analysis. Eur Respir J. 2016 Jun;47(6):1861-4.

8. Catarinella FS, Nieman FH, Wittens CH. An overview of the most commonly used venous quality of life and clinical outcome measurements. J Vasc Surg Venous Lymphat Disord. 2015 Jul;3(3):333-40.

9. Panagiotakos DB, Polystipioti A, Polychronopoulos E. Prevalence of type 2 diabetes and physical activity status in elderly men and women from Cyprus (the MEDIS Study) Asia Pac J Public Health. 2007;19(3):22-8.

10. Bennell K, Dobson F, Hinman R Measures of physical performance assessments: Self-Paced Walk Test (SPWT), Stair Climb Test (SCT), SixMinute Walk Test (6MWT), Chair Stand Test (CST), Timed Up \& Go (TUG), Sock Test, Lift and Carry Test (LCT), and Car Task Arthritis Care \& Research Supplement: Special Outcomes Volume 63, Issue Supplement S11, pages S350-S370,November 2011
11. Fiebig A, Krusche P,Wolf A, et al. Heritability of chronic venous disease. Hum Genet 2010 127:669-674

12. Andreozzi GM, Cordova R, Scomparin MA, et al. Quality of life in chronic venous insufficiency. Int Angiol 2005;24:272-7.

13. Franz A, Wann-Hansson C. Patients' experiences of living with varicose veins and management of the disease in daily life. $\mathrm{J}$ Clin Nurs. 2016 Mar;25 (5-6):733-41.

14. Catarinella FS, Nieman FH, Wittens CH. An overview of the most commonly used venous quality of life and clinical outcome measurements. J Vasc Surg Venous Lymphat Disord. 2015 Jul;3(3):333-40.

15. Catarinella FS, Nieman FH, Wittens $\mathrm{CH}$. The relation between clinical scores and quality of life in long-term follow-up. Phlebology. 2016 Mar;31(1 Suppl):99-105.

16. Dias TYAF, Costa IKF, Melo MDM, et al. Quality of life assessment of patients with and without venous ulcer. Rev Lat Am Enfermagem. 2014 Jul-Aug; 22(4): 576-581.

Received: $14 / 08 / 2018$

Accepted: 28/08/2018

Published: 15/09/2018

Disclosure and conflicts of interest:

The authors declare no conflict of interest.

Corresponding author:

Sema Özberk

Mail: fztsemaozberk@gmail.com 